\title{
Article
}

\section{Holding and restraining children for clinical procedures within an acute care setting: an ethical consideration of the evidence}

Bray, Lucy, Snodin, Jill and Carter, Bernie

Available at http://clok.uclan.ac.uk/12759/

Bray, Lucy, Snodin, Jill and Carter, Bernie ORCID: 0000-0001-5226-9878

(2014) Holding and restraining children for clinical procedures within an acute care setting: an ethical consideration of the evidence. Nursing Inquiry, 22 (2). pp. 157-167. ISSN 13207881

It is advisable to refer to the publisher's version if you intend to cite from the work. http://dx.doi.org/10.1111/nin.12074

For more information about UCLan's research in this area go to http://www.uclan.ac.uk/researchgroups/ and search for <name of research Group>.

For information about Research generally at UCLan please go to http://www.uclan.ac.uk/research/

All outputs in CLoK are protected by Intellectual Property Rights law, including Copyright law. Copyright, IPR and Moral Rights for the works on this site are retained by the individual authors and/or other copyright owners. Terms and conditions for use of this material are defined in the policies page. 


\section{Holding and restraining children for clinical procedures within an acute care setting: An ethical consideration of the evidence}

\section{ABSTRACT}

This critical reflection on the ethical concerns of current practice is underpinned by a systematic synthesis of current evidence focusing on why and how children are held or restrained for clinical procedures within acute care, and the experiences of those present when a child is held against their wishes. Empirical evidence from a range of clinical settings internationally demonstrate that children are held frequently for procedures to be completed; younger children and those requiring procedures perceived as urgent are more likely to be held. Parents and health professionals express how holding children for procedures can cause feelings of moral distress expressed as uncertainty, guilt, and upset and that this act breaches the trusting and protective relationship established with children. Despite this, children's rights and alternatives to holding are not always respected or explored. Children's experiences and perceptions are absent from current literature. Children and young people have a moral right to have their voice and protests heard and respected and for these to inform judgements of their best interests and the actions of health professionals. Without robust evidence, debate and recognition that children are frequently held against their wishes in clinical practice for procedures which may not be urgent, children's rights will continue to be compromised.

\section{KEY WORDS}

Restraint, clinical holding, children, hospital, narrative synthesis, ethical review, child-centred, restriction

\section{INTRODUCTION}

Children and young people find attendance and admission to hospital for clinical procedures frightening and anxiety provoking (Dahlquist et al 1986, Hart \& Bossert 1994, Kain et al 2007, Jaaniste et al 2007, Ersig et al 2013). Although distraction, analgesia and parental presence can be used to improve the experiences of children and young people having procedures within an acute environment (Kleiber \& Harper 1999, Fanurik et al 2000, Piira et al 2005), they are not infallible and there is little evidence-based guidance about how to act if a situation escalates and the first choice of intervention is ineffective. Many episodes of clinical care still rely solely on holding children and young people in order to complete the procedure, despite the availability of alternative and positive strategies. This over-reliance on holding children in order to undertake and complete a procedure raises many ethical and moral issues that often appear to be overlooked within the acute setting. This 
NIN-13-08-R-0080-R1

paper will systematically review the current evidence and consider how children's rights to choice (respect for persons) and not to be harmed are contextualised alongside health professionals' obligation, duty to care and to act in the best interests of children and young people.

\section{BACKGROUND}

The use of holding or restraint within the care of children and young people spans many disciplinary settings, including residential care, psychiatric, secure, criminal justice and health care settings. Arguably, the use of restraint and holding is less institutionally pervasive than in previous periods in time when less consideration was given to holding children. Despite this, children are still held in order for clinical procedures to be completed. Within health care settings, being held or restrained can be a highly traumatic and distressing experience for children, parents (McGrath et al 2002) and health professionals (Huang \& Chuang 2007, Ives \& Melrose 2010, Smith \& Bowman 2009, Bigwood \& Crowe 2008). Being restrained can result in children experiencing short term distress and long term negative psychosocial development (Brenner 2013). Whilst the literature identifies negative outcomes such as distress and trauma, there has been almost no attempt to use a critical ethical lens through which to consider the event of holding and its potential sequelae. Where ethics is discussed, for example in professional guidance documents, this is usually done simply by referring to the principle of best interests.

Some professional bodies provide guidance outlining key principles when undertaking procedures with children (Royal College of Nursing, RCN), but provide little research evidence to guide child health professionals in how to hold children for procedures, which can leave practitioners uncertain about this aspect of practice. There is a stronger evidence base underpinning practice and professional guidance within other disciplines such as elderly care (RCN 2008), child and adolescent mental health (NICE 2005, Quality Network for Inpatient CAHMS 2009), secure settings (National Offender Management Service 2011) and learning disabilities (Department of Health 2002). Uncertainty can be exacerbated by the lack of consensus in the terminology used to describe the holding of children within acute care environments. Terms such as therapeutic holding, restraint, restriction, physical restriction, immobilisation, comfort positioning and clinical holding are used interchangeably. A continuum exists with clinical holding at the lower end being the purposeful restriction of movement of a child using limited force in order to help children, with their permission, to manage a painful procedure quickly or effectively (RCN 2010). At the other end of the continuum is restraint where reasonable force is positively applied against resistance to either restrict movement or mobility or to disengage from harmful behaviour displayed by an individual; restraint should only be used to prevent 
serious harm. Within this review the terms used will relate to those used within the reported published paper. This paper sought evidence to answer the following questions;

What evidence underpins why and how children and young people are held for clinical procedures within an acute hospital care setting?

What are the experiences of children, young people, parents and health professionals of being involved in a clinical holding incident?

What are the ethical concerns associated with holding a child or young person for a procedure against their wishes?

\section{REVIEW METHODS}

A narrative synthesis approach was adopted which allowed the integration of qualitative and quantitative evidence in order to provide an account of current evidence within this field (DixonWoods et al 2005). This paper aims to go beyond a summary of the evidence through a systematic approach to seeking and appraising the current empirical evidence about being held for procedures within an acute children's care setting and by our focused and critical attention to the ethical concerns that co-occur when children are held.

The review adopted a comprehensive and rigorous search in 2013. The authors attempted to source any paper which reported empirical data relating to children and young people (aged under 18 years of age) being held for clinical procedures within acute care settings. Eighteen years of age was carefully chosen to reflect the age at which many young people in the UK and other countries remain as patients within children's acute services. This structured search used electronic bibliographic databases (CINAHL, Pubmed, EMBASE and PsychInfo) complemented with hand searching of reference lists from relevant studies, key journals and citation searching. This initial search resulted in 3,345 papers being identified, of these, a large number of papers were excluded $(3,258)$ as the search terms 'immobilisation' retrieved orthopaedic fracture management studies, and 'restraint' retrieved studies relating to car seat development. Studies were excluded if they reported on child and adolescent mental health settings as these settings are governed by discrete guidance (Quality Network for Inpatient CAHMS 2009). Studies were also excluded if they related to dental care or immunisations within community care practice. While findings from both of these settings could have added depth to the review, they are intrinsically different to the hospital-based environment of most concern to this study. 
NIN-13-08-R-0080-R1

Data were extracted and variables were entered into an electronic proforma; which attended to quality indicators such as methodological approach, sampling, adequacy of reporting and appropriate ethical approvals. Data extraction was conducted by two researchers to minimise bias and increase reliability (CRD 2008). Any discrepancies were discussed, the paper revisited and consensus reached on whether the paper should be included in the review. The review did not adopt an approach which prioritised some research designs over others and all relevant papers which met the core quality criteria were included in the review.

\section{FINDINGS}

The robust search resulted in 29 papers being included in the review; these papers were clinically and methodologically diverse and were published between 1993 and 2013. Most papers collected data from within the United Kingdom or the United States of America; the remaining papers were from Australia, Ireland, Turkey, Kuwait, Greece, Japan, India, Sweden and New Zealand. A wide range of acute clinical settings were represented including critical care, emergency departments, radiology departments, anaesthetic departments, children's wards and oncology units. The findings are organised into three sections: the reported prevalence of children and young people being held within different clinical settings; the decisions which influence children and young people being held for procedures; and the experiences of those involved.

\section{Holding children for procedures: 'it happens all the time', but should it?}

Only one study provided a clear definition of what was judged to be holding, otherwise findings reflect subjective and inconsistent descriptions of what constituted holding. The reported prevalence of children and young people being held for procedures varied between different acute care settings and for different procedures. Radiographers reported high rates of holding children for X-ray examinations (84\%, n=110 Graham \& Hardy 2004; 69\%, n=54 Dashti et al 2012), as did health professionals within emergency departments (71\%, $n=89$ children aged 6-24 months, Crellin et al 2011). Findings from Lewis et al.'s (2007) study indicated that only 44\% $(n=194)$ of anaesthetists held the majority of children ( $<1$ year old) for anaesthetic induction; this perhaps reflects the fact that anaesthetists have access to alternative strategies such as gas inhalation that leads to children being held for a very short time or for holding to be avoided. Naber et al (1995) and Bradlyn et al (1993) reported that children were restrained 'frequently' for lumbar punctures. Within critical care settings (paediatric intensive care, neonatal intensive care), 19 out of 28 units (68\%) (Ofoegbu \& Playfor 2005) and 9 out of 24 units (38\%) (Stacey 2000) reported using physical restraint and clinical holding in their practice in order to prevent treatment interference. Critical care nurses identified restraint as the most common method 
NIN-13-08-R-0080-R1

employed to facilitate a painful procedure (Matthew et al 2011). The high incidence of holding suggests that this is a routine element of practice and as such the ethical dilemmas surrounding the practice are potentially muted and over-looked.

The most commonly described approach to holding children and young people for procedures was physical (person-to-person) (Graham \& Hardy 2004, Homer and Bass 2010, Naber et al 1995). Some studies also described devices which had been used to hold children or young people, these included splinting (Crellin et al 2011, Ofoegbu \& Playfor 2005), swaddling (Demir 2007, Graham \& Hardy 2004, Ofoegbu \& Playfor 2005), straps (Demir 2007, Ofoegbu \& Playfor 2005) and commercial devices in radiological settings (Graham \& Hardy 2004, Dashti et al 2012).

Holding children or young people for procedures seems to persist in practice despite increased evidence and awareness of alternatives, such as distraction, that can be positively employed to facilitate the completion procedures. Evidence shows that professionals, across settings and countries frequently overlook alternatives to holding children and young people (range from $41-90 \%$ of professionals) (Runeson et al 2001, Demir 2007, Crellin et al 2011, Graham \& Hardy 2004, Dashti et al 2012). Workload and timing (Demir 2007), nature of the procedure (Crellin et al 2011) and the child's age (Selekman \& Snyder 1995) were reasons reported as influencing professionals' decision to not engage with distraction techniques. It has been suggested that when health professionals are confronted frequently with emotionally distressing situations they become immune to them (Lundqvist \& Nilstun 2007). It becomes an assumption that children will always be afraid of certain procedures, and this prevents health professionals from seeking alternatives and questioning practice (Lundqvist \& Nilstun 2009)

\section{Holding children for procedures: "It can be a difficult decision" which overlooks ethical concerns}

Of the reviewed literature, eleven studies investigated the reported reasons why children and young people are held within acute care settings for procedures to be completed. The studies indicate that holding children is influenced by two main factors:

1. Ensuring safety included reports of ensuring the physical safety of the child and staff, physiological safety through ensuring diagnostic and treatments were administered, the clinical urgency of the procedure needed, and staff shortages.

2. The perceived status of the child focused on the child's age, cognitive ability, and distress.

\section{Ensuring safety}


NIN-13-08-R-0080-R1

Several studies based within children's wards (Robinson and Collier 1997, Selekman \& Snyder 1995), radiography settings (Graham \& Hardy, 2004, Dashti et al 2012) and other acute care settings (Ofoegbu \& Playfor 2005, Snyder 2004, Robinson \& Collier 1997, Smith et al 2011, Dashti et al 2012) suggest that the child's safety (preventing injury from struggling, wiggling or interference with treatment) was the primary reason for a child to be held during a procedure. Safety issues such as staffing shortages were described as increasing the use of mechanical restraints (straps to wrists and/or ankles) which meant that less vigilance was required to prevent children from pulling out tubes and wires (Ofoegbu \& Playfor 2005). The concept of safety referred to in these studies focuses purely on physical safety and little consideration appears to have been given to consider the child's psychological or ethical well-being and safety. Several studies link safety to the perceived urgency or necessity for a procedure to be completed (Graham \& Hardy 2004, Robinson \& Colier 1997, Lewis et al 2007, Homer \& Bass 2010), with professionals more likely to use holding when a procedure was seen as clinically important and urgent (Lewis et al 2007).

The ethical analysis of harms versus benefits (Delaney et al $\mathrm{xx}$ ) seems to imply that holding a child is judged as a 'reasonable harm' in order to achieve the perceived benefit of completing a clinical procedure or preventing treatment interference. This balance becomes more problematic to morally justify when holding is applied for a non-urgent case and/or when excessive force or persistent holding is used. There is little reflection in the literature on practitioners' moral reasoning processes that allow continuation of a non-urgent holding practice which potentially threatens the psychological well-being of the child or young person and/or the core values of the practitioner. Although described as being a difficult decision, it was rarely described as being ethically difficult.

\section{The perceived status of the child: ethical issues in 'play' but over-ridden}

The decision to hold a child in order for a procedure to be completed was influenced by the perceived status of the child; their age, cognitive competence and ability to have a voice and have it heard. These factors resonate with the ways in which children are often 'othered' within society (Lahman 2008) and their moral status is seen as being less than that of an adult and their needs and wishes can be overridden (Carter et al 2014).

The age of a child was described across the studies as the biggest influence on professionals' decision to use restraint or holding (Lewis et al 2007, Graham \& Hardy 2004, Robinson \& Collier 1997, Bradlyn et al 1993). Younger children were more frequently held for procedures. Professionals reported feeling more comfortable holding and overriding the wishes of younger children (ages 0-6 years) than older children (Homer \& Bass 2010, Lewis et al 2007, Selekman \& Snyder 1995, Dashti et al 2012). 
NIN-13-08-R-0080-R1

Judgements seemed to rely on chronological age with no apparent consideration of different developmental levels, children's previous experience and individual circumstances. Whilst judgements to hold a child neither necessarily reflect a child's best interests nor a strong virtue ethics approach to professional decision-making, it does reflect a society which readily accepts parents and health professionals as knowledgeable and competent decision-makers and homogenously frames children as non-competent, vulnerable and incapable based crudely on their age.

Children's protests and distress were generally reported as being of lower importance or relevance than age and clinical need (Graham \& Hardy 2004, Dashti et al 2012) when determining if holding was needed; this again reflects the low status of the child's own voice within the process. Issues of consent, assent and dissent for procedures with children were not widely discussed in the papers. None of the studies reported that written consent was gained from parents for their child to be held, despite it being recognised that parental agreement for holding is important (Homer \& Bass 2010). This omission reflects the routinisation of holding; it is such an everyday part of practice that little attention is paid to it. Where studies directly reported on consent from parents, this either happened verbally (Ofoegbu \& Playfor 2005) or not at all (Runeson et al 2002, Ofoegbu \& Playfor 2005). Health professionals reported they did not obtain consent from parents as this may provoke anger and aggression; their workload prevented time to obtain consent, asking may risk refusal of consent and nurses being unaware of a requirement for consent (Demir 2007). Reference to gaining assent or permission from children is even less evident; reported primarily in terms of children expressing dissent through being upset, rather than assent being perceived as a purposeful process to aid understanding. The critical analysis of choice seems lacking from current practice. Whilst some decisions to hold may need to occur quickly, in many cases there is ample opportunity to discuss holding, gain consent or assent and to adopt a more deliberate approach about whether a child should be held. The timing of clinical procedures seems to be planned according to health professionals' availability and convenience rather than the readiness of the child and family (Lundqvist \& Nilstun 2007).

\section{Holding children for procedures: experiences of children, parents and health professionals}

Few studies explored children's (Snyder 2004) and parents' (McGrath \& Huff 2003, McGrath et al 2002, Alexander et al 2010, Swallow et al 2011, Brenner 2013) experiences of the use of holding or restraint within an acute setting. More evidence exists on health professionals' perceptions and experiences of holding children for procedures.

Health professionals' experiences: A necessary breach of trust 
The belief that holding is a necessary but unwelcome part of working with children is evident in many of the studies (Bricher 1999, Bricher 2000, Lloyd 2008, Homer \& Bass 2010).

Health professionals have acknowledged that holding children can cause more distress for the child than the pain associated with a certain procedure (Collier \& Pattinson 1997, Collier \& Robinson 1997) and being present at a procedure where a child is held can cause nurses' stress and upset (Lloyd et al 2008). Nurses discuss that holding or condoning holding children for procedures breaches the trusting relationship they build up with a child in their care (Bricher 1999). If the 'reasonable harm' argument proposed earlier creates the initial conditions for nurses to hold a distressed child, there may be a concomitant argument for what could be seen as a 'reasonable breach' judgement. This 'reasonable breach' may reflect that the moral distress experienced by the nurse is quickly overcome and shortlived (Lloyd et al 2008). Additionally the experience of distress by the child or young person, parents and nurses may be set against the justification that the hold was a necessary element of a professional's duty of care and in the child's best interests. However, this would seem to be at odds with the notion of ethical caring as described by Nodding's (2003) where the nurse should have a sense of 'must' getting things right for their patients. As Lundqvist \& Nilstun (2009 p120) note, a duty of care extends beyond being "an instrument of medical care" and requires a wider consideration of the moral implications.

Nurses acknowledge that when holding takes place and a procedure does not 'go well' then the 'damage is done' and they recognise that this can make subsequent procedures harder to negotiate (Bricher 1999). However, a short-termist approach where 'damage done' is weighed against current 'reasonable harm' means that the risks of longer-term implications of being distressed and held during procedures are not considered. Providing good preparation, reflecting on the necessity of the procedure, considering the child's or young person's wishes, identifying additional strategies such as play specialists, and having the courage to stop a procedure where holding has gone beyond ethical bounds requires a nurse to act on behalf of the child and these actions have resource and financial implications for both professionals and families.

Studies suggest that experience and familiarity with working with children influences health professionals' decision making, as it appears that strategies in carrying out procedures are learnt through trial and error type learning (Bricher 1999). Experienced nurses have reported that they are more likely to hold children for procedures than more newly qualified nurses (Robinson \& Collier 1997, Demir 2007). It may be that over time institutional and professional norms begin to override and erode individual's personal ethical competence; the emotional upset of children during procedures 
NIN-13-08-R-0080-R1

becoming an accepted and expected part of practice. It seems that holding a child or young person against their wishes to complete a procedure is currently not framed as an ethical or moral issue.

\section{Parents' experiences: Being there but letting them down}

Most of the studies which collected data on who holds children for procedures indicated that parents provide the majority of the holding (McGrath et al 2002, Graham \& Hardy 2004, Homer \& Bass 2010). Parental presence and parents holding their children for procedures has been linked to reduced levels of distress and upset in children (Snyder 2004, Cavender et al 2004, Smith 2011, Matsumori et al 2006) and the supportive presence, participation and involvement of their parents resulted in children being less likely to experience forceful holding (Graham \& Hardy 2004, Nader et al 1995). Parents have expressed a need 'to be there' (McGrath et al 2002) and reported positive experiences of holding their children in directed child-centred ways (Sparks et al 2007). Parents have been observed as having key roles during procedures through providing information, comfort, diversion, distraction (Cavender et al 2004, Smith 2011) and emotional support (Snyder 2004).

However, despite many positive accounts, some parents report conflicting feelings about holding their children. Mothers and fathers of children with long-term conditions have discussed how they argue about 'whose turn it is this time' to hold their child for procedures, with neither wishing to be the one to hold (Swallow et al 2011). Parents who have been involved in holding their child against their child's wishes express this left them feeling as though they had 'let their child down' (Alexander 2010) as this conflicts with the natural parenting instinct to protect their child (McGrath et al 2002). At the extreme end, parents report feeling like accomplices in a crime when they participate in inflicting hurtful procedures on their child; this can be associated with feelings of disempowerment, guilt, regret and anger (Brenner 2013) and emotional distress (McGrath et al 2002). Feelings of anger were often directed towards health professionals who were seen to objectivise their child and focus only on the procedure rather than each child's individual needs (Brenner 2013). However, in Runeson et al's (2002) study, parents were observed overriding their child's wishes (verbal and physical) and actively holding or supporting health professionals to forcibly hold their child for minor procedures including administration of oral medication. This collaboration between parents and health professionals to ignore a child's protests has been theorised as parents adopting the professional's moral standards and acquiescing to the professional's authority in knowing their child's best interests (Lundqvist \& Nilstun 2007).

\section{Children's experiences: Lacking a voice}


NIN-13-08-R-0080-R1

Only one paper in the review consulted directly with children and young people and Snyder et al. (2004) report that children described that being held for procedures caused anger, resistance and discomfort. The evidence in most papers reflects proxy reports of children's experiences from parents and health professionals or through researchers' objectively assessing their levels of distress during procedures on validated scales. Even in the paper which aimed to address children's perspectives, the child's voice is lost with no verbatim quotes and the data from professionals and parents over-riding the data from the children.

\section{DISCUSSION}

This review has systematically analysed the current literature which addresses the holding and restraint of children and young people within acute health settings. The available literature was diverse in terms of methodological approaches, clinical settings and research focus. It seems that although children, regardless of acute health care setting, are reported as frequently being held, there is very little high quality empirical data or critical ethical debate to inform practice. There is a lack of detail about what constitutes clinical holding or restraint within each study, which makes the comparison and synthesis of data challenging. Some studies refer to comfort holding, hugging or 'secure cuddling' (Homer \& Bass 2010, pg 644) to prevent children from 'wiggling away' (Smith 2011, pg189) whereas others are more explicit in using the term holding or restraint. However, it is not clear what differentiates these terms or approaches. Assessments of holding, restraint and restriction continue to be based on subjective opinions. The lack of robust evidence and clear definitions of what constitutes holding and restraint perpetuate this being an almost invisible, inevitable and taken for granted aspect of children's care within acute settings.

There is little theoretical discussion or ethical reflection regarding children or young people being held for clinical procedures, and little reference to children's rights and agency. Although health professionals may recognise that restraint violates children's rights, (Demir 2007), or that holding people down may be legally questionable (McGrath et al 2002) this does not appear to alter their actions. As within other settings where children are restrained it is unclear whether adults' and institutional interests override those of the child's (NOMS 2011). The child's rights afforded to them by the UN Convention on the Rights of the Child (1989) to have their views listened to and respected are not evident in much of the reviewed literature. It is argued that children's rights to have their voice heard and respected in matters concerning them, is more aspirational than practical (Carnevale et al 2013). Despite recommendations for children and young people to be involved in decisions relating to all aspects of their care (Children \& Young Peoples' Health Outcomes 2013), they continue to be held for procedures against their will without having their voice heard (Runeson et al 2002). If institutions 
do not develop a strong set of values that acknowledge that children and young people are viewed as have rights and moral status equal to, albeit different from, those of adults then the conditions exist that 'allow' parents and health professionals to ignore protests of dissent and believe they are acting in the child's best interests. 'Best interests' is a fluid concept that is open to abuse. Conceptualisations of children's best interests vary at different periods of history and within different cultures (Lansdown 2000) and can be difficult to define (Carnevale et al 2013). A crude enactment of 'best interests' may simply be a poor excuse to 'get the job done'; there is sufficient evidence from the literature that there is a pervasive belief within acute care that children's best interests are served by a procedure being completed despite upset and distress (Lundqvist \& Nilstun 2007).

The view of children as 'becomings' rather than 'beings' means that they can be judged to be in need of protection, dependent (Carnevale et al 2013), incompetent and lack understanding of what constitutes their best interests (Freeman 2011). Instead assumptions about children's abilities need to be challenged and they need additional support to ensure that they are involved in decisions and choices about their care (Carter et al 2014). Recognising children's or young peoples' rights to be heard does not 'mean that their views will always prevail' (Lansdown 2000, pg 286), but that their views should at least inform decisions about them in a purposeful and considered way.

Some children are particularly vulnerable to having their voice and opinions marginalised. Younger children and those requiring urgent treatment were more likely to be held in order for procedures to be completed. This aligns with the increased use of restraint with younger children in other settings such as mental health facilities (Stewart et al 2013). The chronological age of a child rather than the child's levels of distress commonly guided professionals' decisions to restrain or hold a child; with younger children being particularly vulnerable to be perceived as 'less than' and their best interests decided by the adults surrounding them during the procedure. This is despite evidence to suggest that if young children are engaged in a developmentally appropriate way they can make choices and decisions about their care (Alderson 2007). Holding children for non-urgent procedures despite their distress currently seems to be instrumentally justified by it being in the child's best interests; however, this approach primarily focuses on the task and takes little account of a more genuine way of engaging with and nursing the child.

Parents and health professionals report being uncertain, upset, guilty, angry, regretful and uneasy about perpetrating the holding of children for clinical procedures, but seem in many cases unable to explore alternatives, or work to change institutions and health care systems which collude in the continued holding of children. The health professionals seem to display feelings of moral distress (REF), although their distress does not seem to be based on a strong feeling that they have been 
prevented from acting or doing what they perceive to be the 'right thing' (McGrath et al 2002; McGrath \& Huff, 2003; Brenner 2013). Their reports of upset and anxiety are generally short-lived (REF) and it seems that their individual ethical competence (Larkin 1999) and moral agency (REF); their ability to engage in ethically appropriate actions to respect patient's rights (Poikkeus et al 2013) has become eroded by institutionalised unquestioned practice. This has been described as professionals finding 'ethical shelter' within an institution's moral beliefs at the detriment of their own ethical ideals (Lundqvist \& Nilstun 2009). The issue of holding although described using terms such as unpleasant and upsetting, could be viewed by some as being abusive towards children, who should be afforded the right to be protected and cared for within healthcare institutions. Institutional abuse has been defined as; 'any system, program policy, procedure, or individual interaction with a child in placement that abuses, neglects, or is detrimental to the child's health, safety, or emotional and physical wellbeing or in any way exploits or violates the child's basic rights' (Gil 1982 p. 9). Using this definition, holding children against their wishes could be seen to constitute institutional abuse. It is argued that this is not purposeful, but is supported by ethical and moral uncertainty which underpins the uncontested everyday practice of children being held for interventions and procedures. Children's interests can become lost within the 'broader moral landscape' of others interests including those of their parents, professionals and institutions (Carnevale et al 2013, pg 7). The recent report within the UK exploring patient safety (National Advisory Group on the Safety of Patients in England 2013, pg 10) discusses the need to 'recognise with clarity and courage the need for wide systemic change' and how such changes and examination needs to be underpinned by the voice of patients. This is likely to require conditions in which professionals, parents, children and young people can voice concerns about restraint and holding within acute care and question why alternatives to holding are not always considered.

Current evidence suggests that practice is complex and many factors influence how and why children are held or restrained within acute clinical practice. The notion of scales and the influence or 'weight' of different aspects of practice is useful to demonstrate how currently practice is 'tipped towards' the power and authority of adults and institutions. Children's best interests, voice, and perceptions are given little 'weight' within these encounters (see figure 1).

Figure 1: Diagrammatic representation of clinical holding approaches within acute clinical care

\section{INSERT FIGURE HERE}

In order for this imbalance to be addressed, children need to be afforded the right to be involved in decisions and choices about procedures and whether they want or do not want to be held. These choices should be centred around their best interests rather than the interests of the adults or 
institutions. The findings of this review suggest that parents, professionals and children need to work together in an informed way to ask 'is there a better way we can do this?' By doing so, this invisible, inevitable and taken for granted aspect of care will be made visible, measureable and something which can be challenged.

\section{Conclusion}

This narrative synthesis and ethical discussion contributes to the field of practice by adopting a rigorous and critical approach to the presentation of the current evidence relating to children being held for procedures and interventions within acute clinical practice. There is evidence of insufficient engagement with children and, typically, they are not consulted about their experiences, perceptions or their care within current studies, their voices are continually subsumed by parents and health professionals. There is a need for further research exploring both children's and young people's perceptions and a critical ethical exploration of how children's best interests are balanced against their autonomy and developing agency. The paper proposes that current practice is 'tipped towards' institutional norms and adults' best interests with children's rights being afforded less 'weight'. The morally questionable practice of holding children for non-urgent procedures despite their distress is reported to be justified if it is in the child's best interests. However, there is little evidence of a reflexive or ethical stance being adopted to question whether this justification is rationale, reasonable or appropriate. There is need for greater critical reflexivity surrounding this uncontested and invisible aspect of clinical practice.

\section{$\underline{\text { References }}$}

Alexander, E., Murphy, C., \& Crowe, S. (2010). What parents think about physical restraint of their child to facilitate induction of anesthesia. Pediatric Anesthesia, 20(11), 1056-58.

Bradlyn, A. S., Harris, C. V., Ritchey, A. K., Olsen, B. R., Heffer, R. W., Lewallen, J., et al. (1993). Children's reactions to invasive medical procedures: The potential importance of procedure, age, and physical restraint. Journal of Psychosocial Oncology, 11(2), 1-18.

Brenner, M. (2007). Restraint in children's nursing: Addressing the distress. Journal of Children's and Young People's Nursing, 1(4), 159-162. 
NIN-13-08-R-0080-R1

Brenner, M. (2007). Child restraint in the acute setting of pediatric nursing: An extraordinarily stressful event. Issues in Comprehensive Pediatric Nursing, 30(1-2), 29-37. doi:10.1080/01460860701366658

Bricher, G. (1999). Children in the hospital: Issues of power and vulnerability. Pediatric Nursing, 26(3), $277-82$.

Bricher, G. (1999). Paediatric nurses, children and the development of trust. Journal of Clinical Nursing, 8(4), 451-58.

Cavender, K., Goff, M. D., Hollon, E. C., \& Guzzetta, C. E. (2004). Parents' positioning and distracting children during venipuncture effects on Children's pain, fear, and distress. Journal of Holistic Nursing, 22(1), 3256.

Crellin, D., Babl, F. E., Sullivan, T. P., Cheng, J., O'Sullivan, R., \& Hutchinson, A. (2011). Procedural restraint use in preverbal and early-verbal children. Pediatric Emergency Care, 27(7), 622-7.

Dashti, M., Al-Abbad, M., Faleh, A., \& Al-Ostath, S. (2012). Current immobilization implementation of pediatric patients in five major public hospitals in Kuwait: a prospective study into policies and guidelines for radiology departments. Indian Journal of Innovations and Developments, 1(8), 647-52.

Demir, A. (2007). The use of physical restraints on children: Practices and attitudes of paediatric nurses in turkey. International Nursing Review, 54(4), 367-74.

Department of Health (2002) Guidance for restrictive interventions: How to provide safe services for people with learning disabilities and spectrum disorder, London: $\mathrm{DH}$

Dixon-Woods, M., Cavers, D., Agarwal, S., Annandale, E., Arthur, A., Harvey, J., et al. (2006). Conducting a critical interpretive synthesis of the literature on access to healthcare by vulnerable groups. BMC Medical Research Methodology, 6(1), 35.

Folkes, K. (2005). Is restraint a form of abuse? Paediatric nursing, 17(6), 41.

Frank, L., Longo, A., \& Hensley, B. (2011). Evaluating the application of knowledge: The use of restraints. Journal of Pediatric Nursing, 26(3), 259-61. 
NIN-13-08-R-0080-R1

Gil, E (1982) Institutional abuse of children in out-of-home care. Child and Youth Services 4, 7-13

Graham, P., \& Hardy, M. (2004). The immobilisation and restraint of paediatric patients during plain film radiographic examinations. Radiography, 10(1), 23-31.

Homer, J. R., \& Bass, S. (2010). Physically restraining children for induction of general anesthesia: Survey of consultant pediatric anesthetists. Pediatric Anesthesia, 20(7), 638-46.

Hull, K., \& Clarke, D. (2010). Restraining children for clinical procedures: a review of the issues issues that continue to challenge children's nursing. British Journal of Nursing, 19(6), 346-50.

Jeffery, K. (2010). Supportive holding or restraint: terminology and practice. Paediatric nursing, 22(6), 24.

Lahman, M.K.E. (2008) Always othered: Ethical research with children. Journal of Early Childhood Research, 6, 281-300.

Lewis, I., Burke, C., Voepel-Lewis, T., \& Tait, A. R. (2007). Children who refuse anesthesia or sedation: A survey of anesthesiologists. Pediatric Anesthesia, 17(12), 1134-42.

Lloyd, M., Urquhart, G., Heard, A., \& Kroese, B. (2008). When a child says 'no': Experiences of nurses working with children having invasive procedures. Paediatric Nursing, 20(4), 29-34.

Lundqvist,A.\& Nilstun,T. (2009) Noddings's caring ethics theory applied in a paediatric setting. Nursing Philosophy 10 (2), 113-123

Mantadakis, E., Katzilakis, N., Foundoulaki, E., \& Kalmanti, M. (2009). Moderate intravenous sedation with fentanyl and midazolam for invasive procedures in children with acute lymphoblastic leukemia. Journal of Pediatric Oncology Nursing, 26(4), 217-22.

Mathew, P., Mathew, J., \& Singhi, S. (2011). Knowledge, attitude and practice of pediatric critical care nurses towards pain: Survey in a developing country setting. Journal of Postgraduate Medicine, 57(3), 196-200. 
NIN-13-08-R-0080-R1

Matsumori, N., Ninomiya, K., Ebina, M., Katada, N., Katsuda, H., Kosako, Y., et al. (2006). Practical application and evaluation of a care model for informing and reassuring children undergoing medical examinations and/or procedures (part 2): Methods of relating and practical nursing techniques that best bring out the potential of children*. Japan Journal of Nursing Science, 3(1), 51-64.

McGrath, P., Forrester, K., Fox-Young, S., \& Huff, N. (2002). "Holding the child down" for treatment in paediatric haematology: The ethical, legal and practice implications. Journal of Law and Medicine, 10(1), 84-96.

McGrath, P., \& Huff, N. (2003). Including the fathers' perspective in holistic care. part 2: Findings on the fathers' hospital experience including restraining the child patient for treatment. The Australian Journal of Holistic Nursing, 10(2), 5-10.

National Offender Management Service (2011) Assessment of Minimising and Managing Physical Restraint (MMPR) For Children in the Secure Estate

NICE (2005) Violence: the short term management of disturbed/violent behaviour in psychiatric in patient settings and emergency departments. London: NICE

Naber, S. J., Halstead, L. K., Broome, M. E., \& Rehwaldt, M. (1995). Communication and control: Parent, child, and health care professional interactions during painful procedures. Issues in Comprehensive Pediatric Nursing, 18(2), 79-90.

Noddings N. (2003) Caring. A Feminine Approach to Ethics and Moral Education, 2nd edn. University of California Press, Los Angeles, CA.

Ofoegbu, B. N., \& Playfor, S. D. (2005). The use of physical restraints on paediatric intensive care units. Pediatric Anesthesia, 15(5), 407-11.

Pearch, J. (2005). Restraining children for clinical procedures. Paediatric Nursing, 17(9), 36-38.

Playfor, S., \& Ofoegbu, B. (2005). The use of physical restraints in PICU. Pediatric Critical Care Medicine, 6(2), 243. 
NIN-13-08-R-0080-R1

Quality Network for Inpatient CAHMS (2009) Service Standards (Fifth edition). Royal College of Psychiatrists

Robinson, S., \& Collier, J. (1997). Holding children still for procedures. Paediatric Nursing, 9(4), 12-14.

Royal College of Nursing (2008) 'Let's talk about restraint' Rights, risks and responsibilities. London: RCN

Runeson, I., Hallström, I., Elander, G., \& Hermerén, G. (2002). Children's participation in the decision-making process during hospitalization: An observational study. Nursing Ethics, 9(6), 583-98.

Selekman, J., \& Snyder, B. (1995). Nursing perceptions of using physical restraints on hospitalized children. Pediatric Nursing, 21(5), 460-64.

Smith, A. L., Murray, D. A., McBride, C. J., \& McBride-Henry, K. (2011). A comparison of nurses' and parents' or caregivers' perceptions during pediatric burn dressing changes: An exploratory study. Journal of Burn Care \& Research, 32(2), 185-99.

Snyder, B. S. (2004). Preventing treatment interference: Nurses' and parents' intervention strategies. Pediatric Nursing, 30(1), 31-40.

Sparks, L. A., Setlik, J., \& Luhman, J. (2007). Parental holding and positioning to decrease IV distress in young children: A randomized controlled trial. Journal of Pediatric Nursing, 22(6), 440-7.

Stacey, S., Ames, W., \& Petros, A. (2000). Sedation and restraint practices in UK paediatric intensive cares: A telephone survey. Pediatric Anesthesia, 10(6), 702.

Stewart, S.L., Baiden, P \& Theall-Honey, L (2013). Factors associated with the use of intrusive measures at a tertiary care facility for children and youth with mental health and developmental disabilities. International Journal of Mental Health Nursing 22, 56-68

Swallow, V., Lambert, H., Santacroce, S., \& Macfadyen, A. (2011). Fathers' and mothers' developing skills in managing children's long-term medical conditions: How do their qualitative accounts compare? Child: Care, Health and Development, 37(4), 512-23. 
NIN-13-08-R-0080-R1

Tomlinson, D. (2004). Physical restraint during procedures: Issues and implications for practice. Journal of Pediatric Oncology Nursing, 21(5), 258-63. 